Railroad Operational Performance in the United States.

Author(s): Denver Tolliver, John Bitzan, and Doug Benson.

Source: Journal of the Transportation Research Forum, Vol. 49, No. 3 (Fall 2010), pp. 87-100

Published by: Transportation Research Forum

Stable URL: http://www.trforum.org/journal

The Transportation Research Forum, founded in 1958, is an independent, nonprofit organization of transportation professionals who conduct, use, and benefit from research. Its purpose is to provide an impartial meeting ground for carriers, shippers, government officials, consultants, university researchers, suppliers, and others seeking exchange of information and ideas related to both passenger and freight transportation. More information on the Transportation Research Forum can be found on the Web at www.trforum.org. 


\title{
Railroad Operational Performance in the United States
}

\author{
by Denver Tolliver, John Bitzan, and Doug Benson
}

This paper examines the effects of increased car weights, train size, and distance on railroad operational performance, which is measured in revenue ton-miles per train hour. A statistical model is estimated from Class I data that explains most of the variation in this index, while controlling for commodity and fixed network effects. The results suggest that length of haul, net load, and train size contributed significantly to performance gains from 1987 to 2006. However, train miles per track mile increased by $89 \%$ during the same period, resulting in line and yard congestion.

\section{Introduction}

In 2006, Class I railroads moved 32 million carloads of freight (including 12.3 million trailers and containers) and provided 1.77 trillion ton-miles of service (AAR 2007). Transportation agencies in the United States are hoping to limit the growth of highway congestion in key intercity corridors by keeping freight on rail lines instead of highways (AASHTO 2003). From a multimodal perspective, it is important to understand the factors that have contributed to railroad performance.

Railroad performance could be defined in many ways. In this paper, we have selected a measure that has historically been used by the American Association of Railroads (AAR): net or revenue ton-miles per train-hour. This measure reflects train speed and revenue tonnage and is a composite measure of the capability to efficiently move freight in intercity corridors. Other potential indicators (such as speed, tonnage, or congestion) measure only one aspect of railroad performance.

Many studies have addressed railroad productivity and costs, including Lee and Baumel (1987); Berndt, Friedlaender, Chiang, and Vellturo (1993); Wilson (1997); Martland (1999); Oum, Waters, and Yu (1993); and Bitzan and Keeler (2003). While this paper benefits from this research, it does not attempt to measure railroad multi-factor productivity or cost. Instead, the primary objective is to show the effects of increased car weights, train lengths, and shipment distances on line-haul performance. A better understanding of these factors is important in assessing the performance of surface transportation modes within multimodal corridors.

\section{Performance Index}

The Association of American Railroads publishes an index: net ton-miles per train hour. This index "reflects both the number of tons hauled and the miles traveled during an average hour of a freight train's operation" (AAR 2007). The numerator of this index (net or revenue ton-miles) is a measure of railroad output. A performance objective is to move a given number of revenue ton-miles with the fewest possible train hours. In doing so, both road and yard hours are important. Most cars require switching and blocking services at origin and destination, as well as at intermediate locations (Figure 1). For this reason, the denominator of our index is total road and yard hours (TH), which is different from the AAR's index, which reflects road train hours only.

The trend in revenue ton-miles per train hour (RTM/TH) from 1987 through 2006 is shown in Figure 2. The index increased from 33,108 in 1987 to 40,258 in 1992. The remainder of the period is characterized by ups and downs, with the high value for the period $(44,128)$ being recorded in 2002. The index subsequently declined to 42,618 in 2006 . Nevertheless, it increased by $29 \%$ from 1987 through 2006. 
Figure 1: Abstract Representation of Revenue Ton-Miles/Train Hour

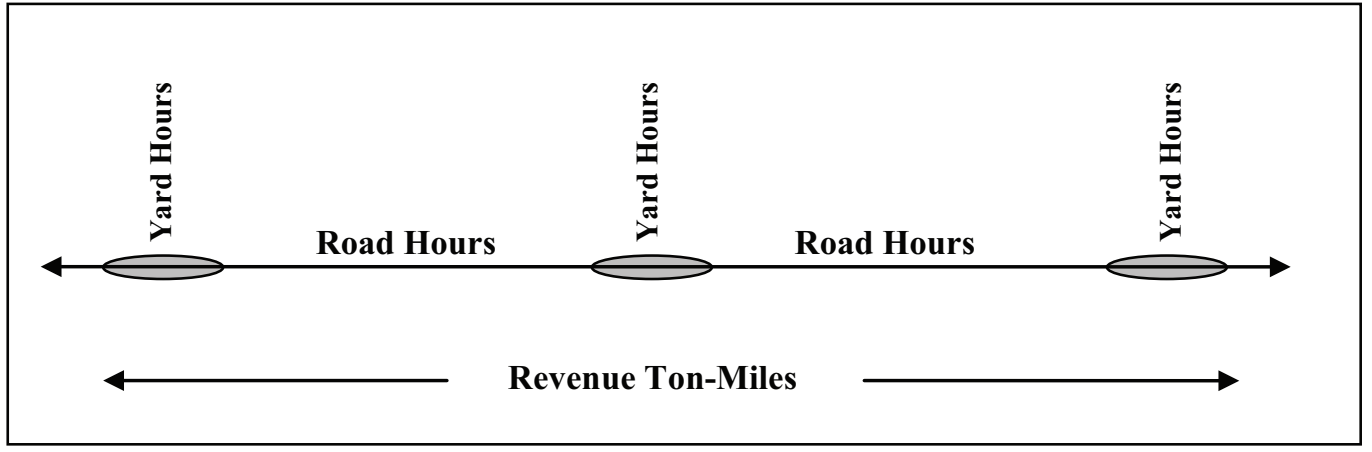

Figure 2: Trend in Operation Performance of Class I Railroads in the United States (Computed from R-1 Reports to the Surface Transportation Board)

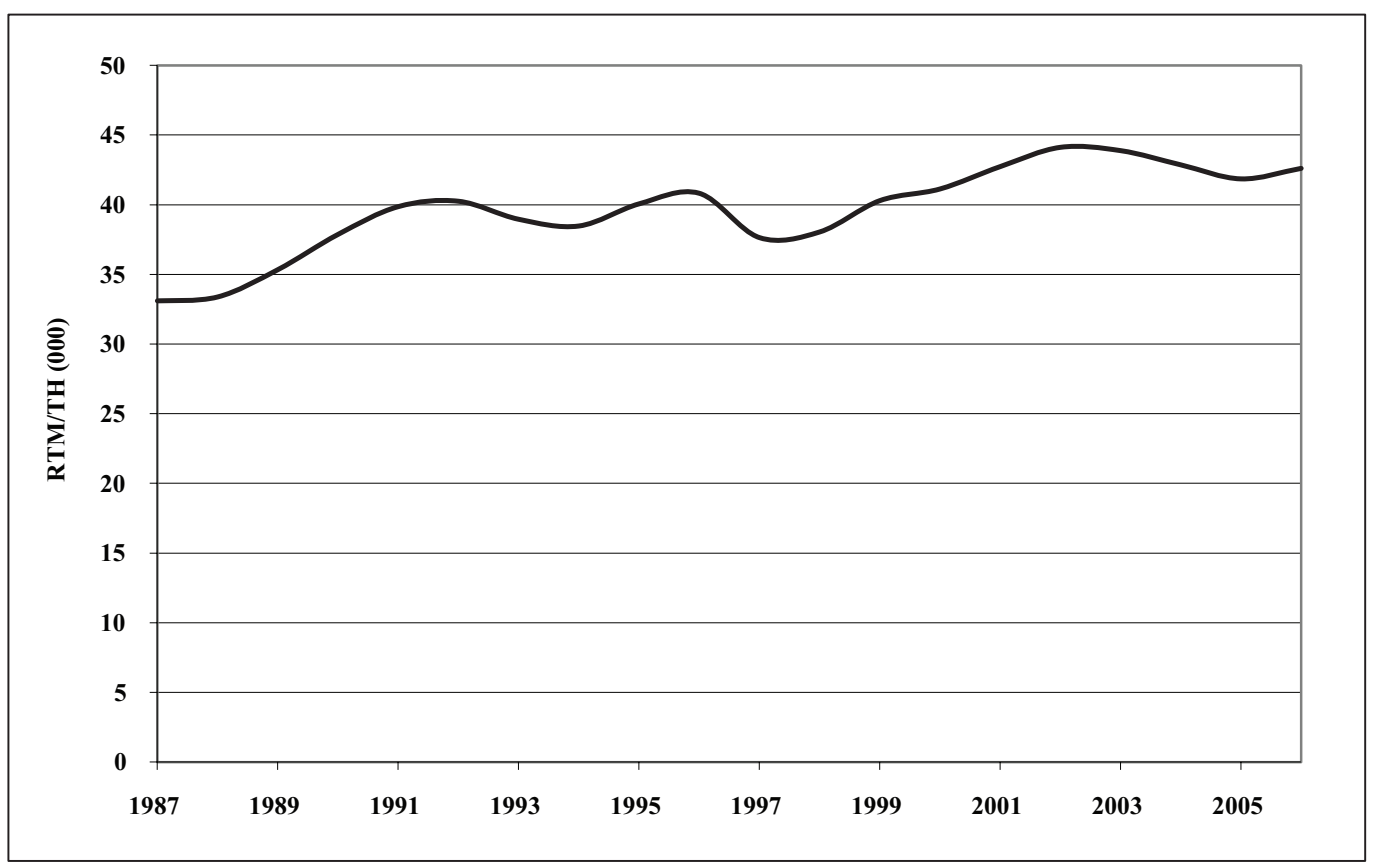

Other performance indicators could have been selected for this study, including train speed, tonnage, or yard dwell time. However, none of these factors are stand-alone or composite indicators. The operational factors (or independent variables) which affect revenue ton-miles per train hour are discussed next.

\section{Density}

Density is a measure of utilization of railroad infrastructure. It can be computed by dividing annual train miles by running track miles. Running track miles include first main tracks; second, third, and fourth main tracks; and passing and side tracks. Collectively, these tracks (along with signal aspects ${ }^{1}$, block lengths ${ }^{2}$, and other traffic control factors) govern the capacities of rail lines.

As shown in Figure 3, train density has risen over time. Train miles per running track mile increased from 1,939 in 1987 to 3,665 in 2006. As traffic increased, railroads added main, passing, and side tracks in high-density corridors. For example, the ratio of second and other main track 
to first main track increased from $14.7 \%$ in 1987 to $19 \%$ in 2006 (computed from R-1 reports). ${ }^{3}$ However, as the chart shows, train miles have been increasing at a faster pace than track miles.

Figure 3: Trend in Train Density in the United States (Computed from R-1 Reports to the Surface Transportation Board)

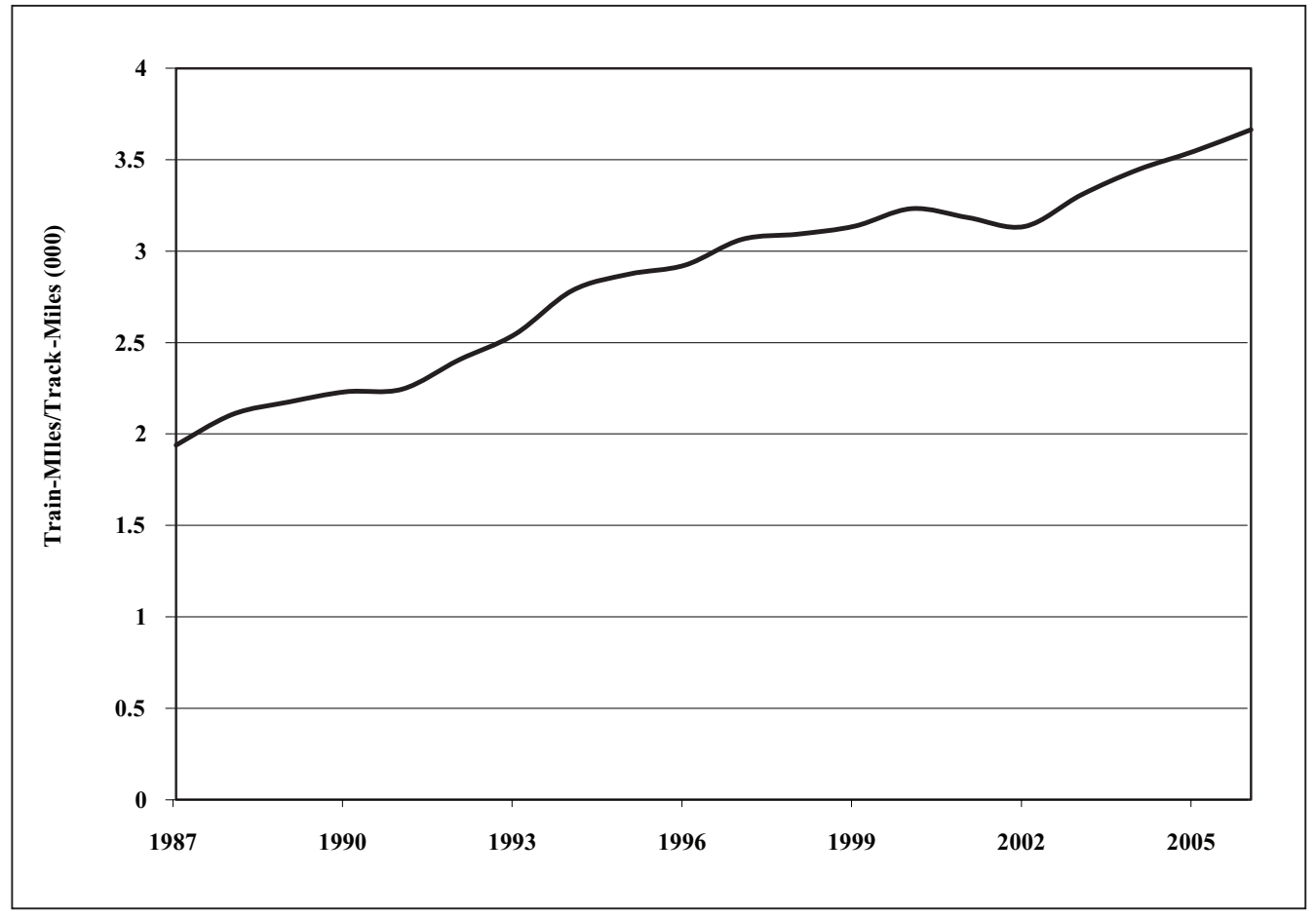

While density is beneficial, additional capacity may be needed as traffic grows. A study by Cambridge Systematics, Inc. (2007) indicates that $12 \%$ to $13 \%$ of U.S. rail lines are at or near capacity. Another $39 \%$ have volume/capacity ratios of 0.4 to 0.7 . With continued traffic growth, $45 \%$ of U.S. rail lines are projected to be near, at, or beyond capacity in 2035 without expansions (Cambridge Systematics, Inc. 2007).

\section{Data Sources}

This paper utilizes 20 years of Class I railroad data from R-1 reports, which are submitted annually to the Surface Transportation Board (STB). This database includes 193 observations from 1987 through 2006. Information for the following railroads are used: Atchison, Topeka, \& Sante Fe (ATSF), Burlington Northern (BN), BNSF, Chicago \& Northwestern (CNW), Conrail (CR), CSX, Grand Trunk Western (GTW), Illinois Central (IC), Kansas City Southern (KCS), Norfolk Southern (NS), Soo Line (SOO), Southern Pacific (SP), and Union Pacific (UP). Some of these railroads were merged during the period and their names are no longer used.

The primary sources of information are Schedules 700 and 755 of the R1 Report and the Quarterly Commodity Statistics (QCS) report. It is a report of the number of carloads and revenue tons handled by each railroad. Operational statistics such as train miles, car miles, and train hours are reported in Schedule 755. Miles of road and running track miles are reported in Schedule $700 .{ }^{4}$ 


\section{OPERATIONAL PERFORMANCE MODEL}

In this section of the paper, a performance model is presented to explain variations in revenue tonmiles per train hour. The model (shown in Equation 1) includes key operational factors such as train size, length of haul, net load, and road and yard congestion.

(1) $R T M / T H=\mathrm{f}(A L H, A V C A R S, N E T, W T R, T D, Y D, M R, C O M M, R R, T)$

Where:

$\mathrm{RTM} / \mathrm{TH}=$ Revenue ton-miles per train hour

$\mathrm{ALH}=\quad$ Average length of haul (miles)

AVCARS $=$ Average cars per freight train

$\mathrm{NET}=\quad$ Net load per freight car (tons)

WTR $=\quad$ Average way train trips per carload

$\mathrm{TD}=\quad$ Train density (train miles per running track mile)

$\mathrm{YD}=\quad$ Yard density (locomotive miles per yard track mile)

$\mathrm{MR}=\quad$ Miles of road

$\mathrm{COMM}=\quad$ A vector of commodity variables

$\mathrm{RR}=\quad$ A vector of railroad indicator variables

$\mathrm{T}=\quad$ Time (years since 1987)

The first six variables are of primary importance. The last four are control variables. They are necessary to account for the effects of mergers, rationalization, network effects, and variations in commodity mix (among railroads and across time). The operational effects of the primary variables, and their expected relationships to revenue ton-miles per train hour, are previewed in the following paragraphs.

\section{Average Length of Haul}

ALH is the average distance that a shipment travels on an individual railroad's network. Because most shipments are interlined, the average distance of a movement on a single railroad is often less than the total shipment distance. As used in this study, ALH is intended to measure the effect of longer hauls on the efficiency of an individual railroad. The sign of ALH is expected to be positive for several reasons: (1) Interchange frequency decreases with mergers that increase ALH. (2) The yard hours required to originate and terminate a shipment are spread over more line-haul miles, resulting in economies of distance. As shown in Figure 4, average length of haul has increased since 1987 as a result of mergers, growth in export/import traffic, and other market factors. The effects of mergers between 1995 and 1999 are apparent in Figure 4.

\section{Average Cars per Train}

Maximum train length (i.e., the longest feasible train) is constrained primarily by safety and physical constraints, such as the lengths of side tracks. Maximum train length is the upper bound of average train length. However, average train length (which is measured in cars per train) is influenced by many factors other than maximum length, including network and route densities and commodity mix. Because longer trains utilize time more effectively, AVCARS is expected to have a positive sign.

An analysis of R-1 report data reveals that substantial variations in cars per train were observed during the period - both within and across railroads. Average cars per train ranged from 47.2 to 86.7. The overall mean (for all railroads) was 68.4 cars. The standard deviation was 9.4. 
Figure 4: Trend in Average Length of Haul on Individual Railroads in the United States (Source: Computed from R-1 Reports to the Surface Transportation Board)

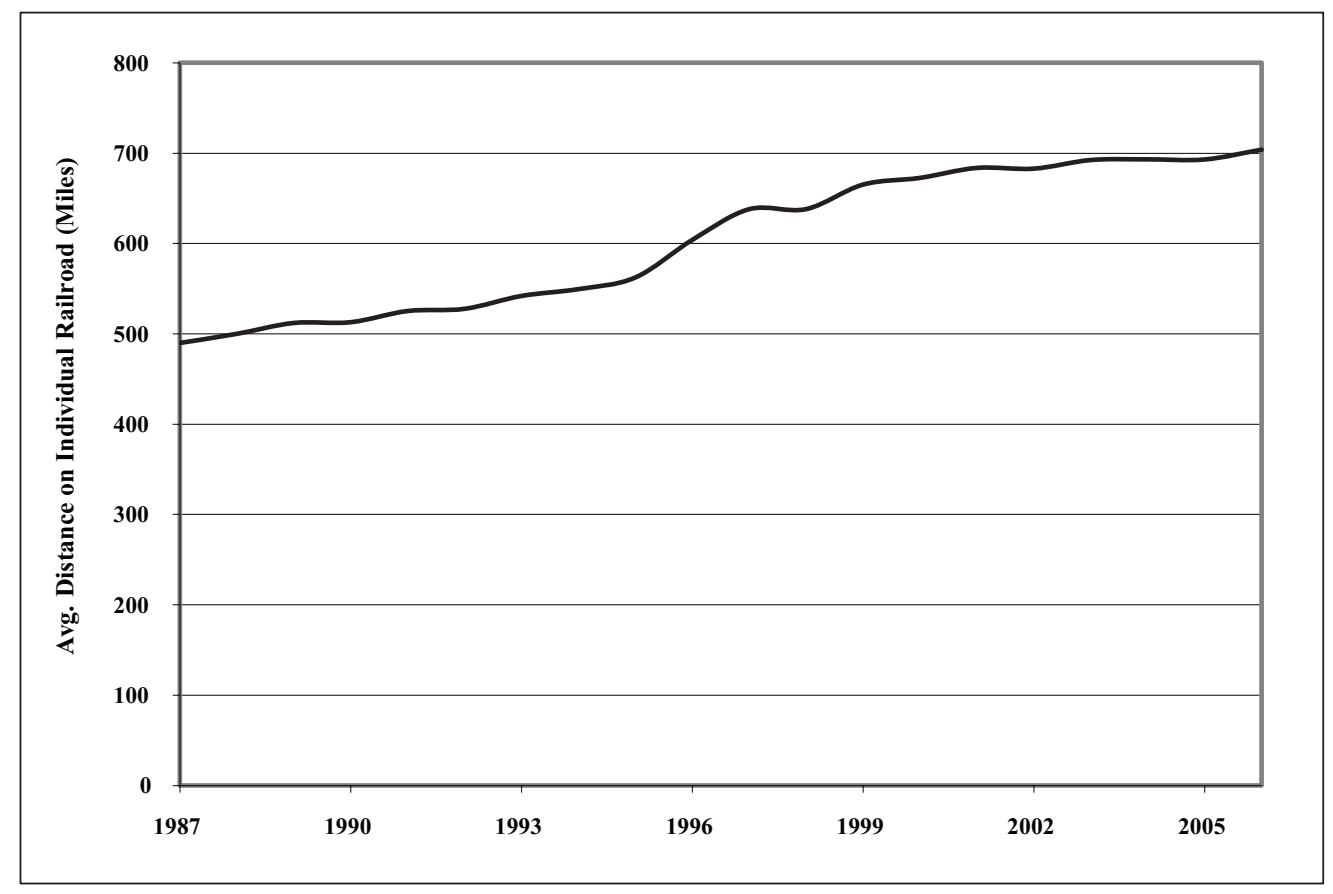

\section{Net Load}

The net load per car (NET) is computed by dividing the revenue tons of freight handled on an individual railroad by the carloads. Logically, this variable is expected to have a positive sign in the model.

An analysis of R-1 report data reveals that substantial variations in tons per car were observed during the 1987-2006 period-both within and across railroads. Average tons ranged from 44.9 to 101.6. The overall weighted mean was 65.1 tons. The standard deviation was 8.0.

\section{Train Service}

Generally, railroads operate three types of trains: way, through, and unit. Single cars usually travel in way trains at origin and/or destination. Way trains are small trains that operate primarily between remote stations located on branch lines and railroad yards. They stop frequently at stations to drop off and pick up cars. In contrast, through trains move from yard to yard and perform little or no switching en route. Unit train service is "a specialized shuttle-type service in equipment (railroad or privately owned), dedicated to such service, moving between origin and destination."

Way and through train services are not independent. In most cases, a way train movement precedes or follows a through train movement. However, unit and way train services are mutually exclusive for a given shipment or class of traffic. These relationships are considered in the definition of the variable WTR, which is defined as the ratio of carloads handled in way trains to total carloads originated and terminated. WTR increases with the proportion of carloads handled in non-unit train service. Conversely, WTR decreases as the proportion of carloads moved in unit trains increases. WTR is expected to have a negative sign. 


\section{Density}

The density variable used in the study (train miles per running track mile) was described earlier. Because increasing densities may reflect line congestion and more train-hours per revenue tonmile, this variable is expected to have a negative sign. In addition to line congestion, railways may experience yard congestion as facilities are consolidated and traffic grows. In this study, yard density is measured in locomotive-miles per yard track mile (YD). The variable YD is expected to have a negative sign in the model, indicating some yard congestion during the period.

\section{Miles of Road}

According to R-1 data, miles of road (or route miles) is the length of all rail lines regardless of the number of tracks. Miles of second, third, and fourth main tracks; crossovers and passing tracks; and side tracks are excluded from this measure. Miles of road can be increased through mergers and decreased through abandonment, consolidation, or sales. Miles of running track can be increased on parts of a carrier's system, while miles of road are decreased on others.

Miles of road and track reflect the miles operated by a given railroad. Because some segments are operated by more than one company, the sum of the miles operated for the industry as a whole may be greater than the sum of the miles owned. However, all activity measures (such as train miles and car miles) reflect train movements over operated segments. Therefore, the track and operational data used in this study are consistent.

According to R-1 data, miles of road decreased from 144,230 in 1987 to 119,684 in 2006 as a result of abandonment, the consolidation of lines after mergers, and the sale of branch lines to local and regional railroads. Over time, traffic has been concentrated on fewer lines. As a result, Class I carriers have been relieved of the time-intensive tasks of picking up and delivering freight on low-density lines. For the most part, these tasks are now performed by local operators with lower overhead costs and more flexible scheduling.

Miles of road should have a negative sign in the model, indicating that the elimination of less productive route miles has improved the efficiency of train operations. However, miles of road may capture several effects. The route miles of some railroads jumped dramatically after mergers. In this respect, MR is an important control variable.

\section{Commodities}

The commodity variables are control variables. They do not directly explain operational efficiency. However, they may account for unique industry shipping patterns. Although railroads haul many commodities, 14 Standard Transportation Commodity Code (STCC) groups comprise 99\% of the freight tonnage originated by U.S. Class I railroads. A commodity variable is defined for each of the 14 STCC groups shown in Table 1. Each variable represents the commodity's share of total tons handled by a railroad. In addition, a variable is created for STCC group 42: empty trailers and containers. Although these movements are classified as revenue tons, the only revenue cargo is the tare weight of the trailer or container. The $16^{\text {th }}$ variable encompasses all other commodities. To avoid singularity, only 15 of the variables are included in the model. ${ }^{6}$

\section{Accounting for Mergers, Acquisitions, and Other Changes Over Time}

Average length of haul (described earlier) accounts for increased efficiencies from longer hauls and reductions in interchange switching - both of which result from end-to-end mergers. However, other effects of mergers (such as network efficiencies) are accounted for through railroad indicator variables. 
Table 1: Primary Commodities Transported by U.S. Class I Railroads

\begin{tabular}{lc}
\hline Commodity & Percent of Tons Originated \\
\hline Coal & 43.5 \\
Chemicals \& allied products & 8.6 \\
Farm products & 7.6 \\
Non-metallic minerals & 7.2 \\
Misc. mixed shipments & 6.4 \\
Food \& kindred products & 5.4 \\
Metals \& products & 3.2 \\
Metallic ores & 3.1 \\
Petroleum \& coke & 2.8 \\
Stone, clay \& glass products & 2.7 \\
Waste \& scrap materials & 2.5 \\
Lumber \& wood products & 2.2 \\
Pulp, paper \& allied products & 1.9 \\
Motor vehicles \& equipment & 1.7 \\
\hline
\end{tabular}

Source: AAR. Railroad Facts, 2007 Edition.

Each Class I railroad that existed during the 1987-2006 period is represented by an indicator variable - e.g., KCS. When the observation is for the Kansas City Southern Railway, KCS equals one. Otherwise, KCS equals zero. Additional indicator variables are defined for mergers. For example, the UP system includes three railroads that appear in the database: UP, SP, and CNW. CNW was acquired by UP in 1995. Union Pacific merged with Southern Pacific in 1997. In the analysis, UPCNW assumes a value of one in 1995, and each year thereafter - but is zero otherwise. Similarly, the variable UP-SP assumes a value of one in 1997, and each year thereafter - but is zero otherwise.

Analogous variables are defined for other mergers or acquisitions. For example, Burlington Northern merged with ATSF in 1996 to form BNSF. CSX and NS acquired parts of Conrail in 1999. In 2002, the Canadian National Railway consolidated ICG, GTW, and other rail lines into the Grand Trunk Corporation (GTC). In the Grand Trunk system, GTC is one if the year is 2002 or later; however, GTC is zero otherwise. The ICG indicator variable assumes a value of one when GTC is one, or when the observation is for the old ICG prior to 2002. The GTW variable works in a similar manner.

Collectively, the railroad indicator variables account for the unique characteristics of each railroad's system and changes in network characteristics resulting from mergers. However, all changes from 1987 to 2006 cannot be captured with aggregate data. Many innovations occurred in train location technology, centralized traffic control, computerization of locomotives, and systems modeling. These "other influences" are captured in the time variable (T), which is an integer that represents the elapsed time in years since 1987 . $\mathrm{T}$ is expected to have a positive sign, indicating that railroad operational efficiency has been increasing over time.

\section{STATISTICAL MODEL AND RESULTS}

The model includes variables of different denominations, and data ranges. A logarithmic form of the regression model is useful for this type of analysis because it allows for easy comparison of effects. The dependent variable is the natural log of revenue ton-miles per train hour. The activity variables, the commodity variables, and time are entered as natural logs - therefore, their estimates are elasticities. The indicator variables (which take values of zero or one) do not affect the slope of the regression surface. Instead, they shift the intercept, and in doing so represent each railroad's unique system factors. 


\section{Main Effects}

The parameter estimates and standard errors of the operational variables are shown in Table 2, along with the t-values and p-values associated with these estimates. A p-value represents the probability of observing a greater absolute value of $t$ if the null hypothesis is true - i.e., the parameter estimate (the partial slope) is not significantly different from zero.

As expected, the signs of ALH, AVCARS, and NET are positive. Moreover, all three variables are highly significant with p-values of less than 0.01 . ALH has the strongest positive influence. The effects are as follows: A $1.0 \%$ increase in length of haul increases operational efficiency by $0.40 \%$. A $1.0 \%$ increase in average cars per train increases operational efficiency by $0.35 \%$. A $1.0 \%$ increase in net load increases operational efficiency by $0.37 \%$.

Table 2: Parameter Estimates and P-Values of Operational Variables

\begin{tabular}{lcccc}
\hline Parameter & $\begin{array}{c}\text { Parameter } \\
\text { Estimate }\end{array}$ & $\begin{array}{c}\text { Standard } \\
\text { Error }\end{array}$ & t Value & Pr $>|\mathbf{t}|$ \\
\hline Intercept & 11.31208 & 1.61563 & 7.00 & $<.0001$ \\
Log of Average Length of Haul (ALH) & 0.40040 & 0.10949 & 3.66 & 0.0004 \\
Log of Average Cars per Train (AVCARS) & 0.35368 & 0.12048 & 2.94 & 0.0038 \\
Log of Net Tons per Car (NET) & 0.36688 & 0.11470 & 3.20 & 0.0017 \\
Log of Way Train Trips per Car O/T (WTR) & -0.06662 & 0.02321 & -2.87 & 0.0047 \\
Log of Roadway Congestion Index (TD) & -0.32073 & 0.08894 & -3.61 & 0.0004 \\
Log of Yard Congestion Index (YD) & -0.15172 & 0.03319 & -4.57 & $<.0001$ \\
\hline
\end{tabular}

As expected, TD and YD have negative signs and are highly significant. A $1.0 \%$ increase in train density results in a $0.32 \%$ decrease in revenue ton-miles/train hour. A $1.0 \%$ increase in yard density results in a $0.15 \%$ decrease in RTM/TH. In addition, a $1.0 \%$ increase in WTR results in a $0.07 \%$ decrease in operational efficiency.

\section{Commodity Effects}

As shown in Table 3, most of the commodity share variables (including coal) are not statistically significant. The unexpected negative sign of the coal variable may be the result of strong correlations with NET, AVCARS, and ALH. Coal unit trains have some of the highest net load factors and the most cars per train.

Three of the commodity share variables are statistically significant with positive signs: lumber products, miscellaneous mixed freight (which is shipped in containers), and pulp \& paper products. Some lumber products are shipped on bulkhead or spine flatcars with achievable net loads of 100 tons. Pulp/paper products include woodchips (which can be loaded to 100 tons in large hopper cars), and newsprint and other paper products that use boxcars. Because boxcars can be reloaded by shippers, they incur relatively few empty miles. Therefore, fewer train hours are required to reposition these cars.

Several trends and efficiencies explain the positive sign of miscellaneous mixed freight: (1) increased use of double-stack flatcars; (2) increased use of 40-foot (versus 20-foot) marine containers; (3) increased use of larger domestic containers; (4) increased use of intermodal express trains; and (5) high utilization of flatcars. The first three trends increase the revenue tons per intermodal flatcar, while the fourth trend reduces the number of train hours required for land- and mini-bridge movements. In addition, intermodal flatcars can be reloaded with containers by the same shippers at origin and destination. Consequently, railroads incur fewer empty line haul or switching miles. 
Table 3: Parameter Estimates and P-Values of Commodity Variables

\begin{tabular}{lcccc}
\hline Parameter & $\begin{array}{c}\text { Parameter } \\
\text { Estimate }\end{array}$ & $\begin{array}{c}\text { Standard } \\
\text { Error }\end{array}$ & t Value & Pr $>|\mathbf{t}|$ \\
\hline Log of Coal Share & -0.04514 & 0.08877 & -0.51 & 0.6118 \\
Log of Chemicals Share & -0.07420 & 0.05837 & -1.27 & 0.2057 \\
Log of Farm Products Share & 0.00623 & 0.04322 & 0.14 & 0.8856 \\
Log of Nonmetallic Minerals Share & -0.09931 & 0.03933 & -2.53 & 0.0126 \\
Log of Food Products Share & -0.11716 & 0.08314 & -1.41 & 0.1608 \\
Log of Misc. Mixed Freight Share & 0.07834 & 0.02563 & 3.06 & 0.0026 \\
Log of Metal Products Share & 0.06417 & 0.04146 & 1.55 & 0.1238 \\
Log of Stone/Clay/Glass Products Share & -0.17032 & 0.05364 & -3.18 & 0.0018 \\
Log of Lumber Products Share & 0.13213 & 0.03463 & 3.81 & 0.0002 \\
Log of Petrol./Coke Products Share & -0.04918 & 0.03556 & -1.38 & 0.1686 \\
Log of Waste Materials Share & -0.06077 & 0.04550 & -1.34 & 0.1836 \\
Log of Motor Vehicles Share & -0.01584 & 0.01875 & -0.84 & 0.3996 \\
Log of Pulp \& Paper Products Share & 0.15435 & 0.06387 & 2.42 & 0.0168 \\
Log of Metallic Ores Share & 0.00051707 & 0.01316 & 0.04 & 0.9687 \\
Log of Empty Containers Share & -0.01667 & 0.00617 & -2.70 & 0.0077 \\
\hline
\end{tabular}

Three of the commodity share variables are statistically significant with negative signs: empty containers; stone, clay, and glass products; and nonmetallic minerals. The first effect (empty containers) is easy to explain. Although the tare weights of containers are classified as revenue freight, their weights are small in comparison with the train hours required to reposition them. The effects of stone, clay, and glass products cannot be easily explained. This STCC group includes a variety of dimensional building materials which are relatively light-loading and move as individual carloads (rather than as unit trains or multi-car shipments). Their dispersed origins and destinations (and small shipment quantities) may result in less efficient train and yard operations-which could partially explain the significant negative sign. Nonmetallic minerals account for most of the railroads' non-revenue ton-miles, including the movement and distribution of crushed stone, riprap, and gravel used in track construction and maintenance. These movements result in train hours but no revenue ton-miles.

\section{Fixed Network and Time-Related Effects}

As shown in Table 4, T is highly significant with a positive sign, indicating that operational efficiency has been increasing over time as a result of technological or managerial innovations not reflected in the activity, commodity, or indicator variables. The effects of mergers are primarily reflected in average length of haul and the indicator variables. ALH accounts for the efficiencies of longer hauls and less-frequent interchange, whereas the indicator variables account for network effects such as combining lines, yards, and traffic control systems; eliminating redundancies and circuitous movements to avoid interchange; and broadening the pool of labor and specialized equipment available to the merged railroad. After controlling for ALH, the signs and parameter estimates of the railroad variables suggest that additional benefits have resulted from mergers.

The sign and estimate of each railroad indicator variable is relative to the variable left out of the equation, which is the unmerged UP railroad. As shown in Table 4, the signs of the two UP merger variables (UP-SP and UP-CNW) are positive and their estimates are greater than those of the individual railroads (SP and CNW). Similarly, the parameter estimate for the merged BNSF railroad is greater than the estimates for the BN or ATSF. Likewise, the estimates for the merged CSX and NS systems (CSX-CR and NS-CR) are greater than the estimates for NS, CSX, or Conrail. 
Moreover, the estimate for the merged GTC system is greater than the estimates for the ICG and GTW railroads. Collectively, these indicator variables suggest that - after controlling for changes in lengths of haul-mergers have resulted in operational efficiency gains.

Table 4: Parameter Estimates and P-Values for Railroad Operational Model

\begin{tabular}{lcccc}
\hline Parameter & Parameter Estimate & $\begin{array}{c}\text { Standard } \\
\text { Error }\end{array}$ & t Value & Pr $>|\mathbf{t}|$ \\
\hline Intercept & 11.31208 & 1.61563 & 7.00 & $<.0001$ \\
Log of Miles of Road (MR) & -0.30520 & 0.08238 & -3.70 & 0.0003 \\
Log of Time (T) & 0.11898 & 0.01453 & 8.19 & $<.0001$ \\
ATSF & -0.29006 & 0.08981 & -3.23 & 0.0015 \\
BNSF & 0.33333 & 0.13874 & 2.40 & 0.0175 \\
BN & -0.30684 & 0.08173 & -3.75 & 0.0002 \\
UP-SP & 0.70667 & 0.15428 & 4.58 & $<.0001$ \\
UP-CNW & 0.97562 & 0.20757 & 4.70 & $<.0001$ \\
SP & -0.70992 & 0.12679 & -5.60 & $<.0001$ \\
CNW & -0.97671 & 0.19178 & -5.09 & $<.0001$ \\
SOO & -1.23953 & 0.19985 & -6.20 & $<.0001$ \\
ICG & -1.45662 & 0.22820 & -6.38 & $<.0001$ \\
GTW & -2.12493 & 0.33796 & -6.29 & $<.0001$ \\
GTC & 2.43181 & 0.38182 & 6.37 & $<.0001$ \\
KCS & -1.40813 & 0.25154 & -5.60 & $<.0001$ \\
CR & -0.87898 & 0.14582 & -6.03 & $<.0001$ \\
CSX & -0.55094 & 0.11366 & -4.85 & $<.0001$ \\
CSX-CR & 0.98397 & 0.16235 & 6.06 & $<.0001$ \\
NS-CR & 0.91573 & 0.16292 & 5.62 & $<.0001$ \\
NS & -0.66424 & 0.10828 & -6.13 & $<.0001$ \\
\hline
\end{tabular}

Another network variable (miles of road) is also statistically significant with a negative sign. There may be several reasons for this result. (1) Miles of road decreased throughout the period, while operational efficiency increased. This suggests that the concentration of traffic on higherdensity lines resulted in more efficient train operations. (2) Many of the miles that disappeared were sold to local or regional railroads that consolidate and distribute traffic on low-density lines. Many of these operations are time-intensive, requiring lengthy switching operations at branch-line stations. In effect, the transfer of lines to local operators relieved Class I railroads of some intensive switching operations. The parameter estimate of -0.30 suggests that (when controlling for changes in length of haul and other network efficiencies gained from mergers) a $1.0 \%$ reduction in miles of road has improved operational performance by $0.30 \%$.

\section{Model Fit and Properties}

This model explains more than $97 \%$ of the variation in operational efficiency (Table 5). The R-Square adjusted for number of independent variables is 0.963 . The F-test for goodness of fit is highly significant. Moreover, the coefficient of variation is less than $1 \%$, indicating a very high level of precision.

Two statistical problems often occur in panel datasets: (1) nonconstant variance and (2) autocorrelation. Nonconstant variance occurs when variability increases with firm size or output. For example, the variance in revenue ton-miles among railroads may increase with output. 
However, the model is essentially one of indexes (e.g., train-miles/running track mile), in which size and activity are scaled. Thus, the null hypothesis is constant variance. The p-value of the chisquare statistic used to test for constant variance is 0.70 . A high p-value indicates there is little evidence to reject the assumption of constant variance. The Durbin-Watson statistic (which tests for autocorrelation) is 2.143 . The probability of a greater value is 0.194 . The probability of a lesser value is 0.806 . These results suggest that serial correlation is not an issue. This conclusion is bolstered by an autoregression analysis in which none of the terms introduced to capture serial correlation were statistically significant.

Table 5: Model and Error Sum of Squares and Goodness of Fit Measures

\begin{tabular}{c|l|c|c}
\hline Line & \multicolumn{1}{|c|}{$\begin{array}{c}\text { Source of Variation } \\
(\mathbf{a})\end{array}$} & $\begin{array}{c}\text { Degrees of Freedom } \\
(\mathbf{b})\end{array}$ & $\begin{array}{c}\text { Sum of Squares } \\
(\mathbf{c})\end{array}$ \\
\hline 1 & Model & 40 & 20.0285 \\
\hline 2 & Error & 152 & 0.5938 \\
\hline 3 & Corrected Total & 192 & 20.6223 \\
\hline & \multicolumn{1}{|c|}{ Mean Square Errors } & Line 1(c) / Line 1 (b) & Value \\
\hline 4 & Model & Line 2(c) / Line 2 (b) & 0.5007 \\
\hline 5 & Error & Line 3(c) / Line 3 (b) & 0.0039 \\
\hline 6 & Total Source & 0.1074 \\
\hline & \multicolumn{1}{|c|}{ Goodness of Fit } & Line 1 (c) / Line 3 (c) & Value \\
\hline 7 & R-Square & $1-[$ Line 5 (c) / Line 6 (c)] & 0.971 \\
\hline 8 & Adjusted R-Square & SQRT(Line 2 (c)) & 0.963 \\
\hline 9 & Root Mean Square Error & & 0.0625 \\
\hline 10 & Mean Value of ln(RTM/TH) & Line 9 (c) / Line 10 (c) * 100 & 10.419 \\
\hline 11 & Coefficient of Variation & Line 4 (c) / Line 5 (c) & $0.60 \%$ \\
\hline 12 & F-Value & & 128.17 \\
\hline 13 & Prob. of $>$ F-Value & & $<.0001$ \\
\hline
\end{tabular}

\section{Qualitative Factors Not Considered}

Although the statistical results are good, it must be recognized that many qualitative factors which influence railroad performance are not reflected in the model. To some extent, management and market influences may show up in the indicator and time variables. Technological factors that cannot be directly quantified may be reflected in the time trend variable - which is highly significant. While commodity/industry effects are represented in the model, institutional and labor factors (such as regulations and work rules) are not; nor are the dual freight and passenger train operations which occur on some lines. All of these factors may affect the revenue ton-miles per train hour that are attainable on certain parts of the railroad system. Nevertheless, the model explains $97 \%$ of the variation in operational performance among railroads over time.

\section{CONCLUSION}

This paper has analyzed the effects of key operational factors on railroad performance, while controlling for commodity and network effects. The results suggest that much of the improvement in performance between 1987 and 2006 was attributable to higher net loads, longer trains, and longer hauls. Other gains may have resulted from mergers and the transfer of branch lines to local and regional operators. The extent to which these trends will continue in the future is unclear. Increases in average lengths of haul are likely if land bridge and unit-train shipments grow proportionally. However, large increases in ALH may not be possible without mergers or consolidations, which are 
unlikely at present. On the other hand, performance may be improved through increases in train size and net load.

According to R-1 data, in 2006 the average train included less than 70 cars. Much longer trains are operationally feasible. To some extent, average cars per train can be increased through greater utilization of unit trains. As more commodities move in unit trains, a corresponding reduction occurs in way train activity. At the same time, net loads can be increased by substituting 286,000-pound and 315,000-pound cars for smaller ones. However, larger cars come with a price. System-wide use of heavier cars may require additional track investments and higher track maintenance costs. For example, Kalay and Guins (1998) estimated that track and bridge costs could increase by more than $20 \%$ on some routes if 315,000 -pound cars are used instead of 263,000-pound cars. However, some of the infrastructure investments needed to support heavier railcars may have been made in recent years.

With growth in traffic, train densities have increased over time. The concentration of railroad traffic has undoubtedly had many benefits. However, the results of this study suggest that road and yard traffic may be at levels which are impacting system performance. This does not mean that all segments of the railroad system are congested. Since traffic is concentrated in certain corridors, it is likely that congestion is primarily a problem on some high-density lines. However, an assessment of the levels of congestion on particular lines cannot be made from this study.

In conclusion, some of the variables responsible for the impressive performance of Class I railroads during the last 20 years have been identified in this paper. However, if the volume/capacity ratios projected by Cambridge Systematics, Inc. (2007) occur, future railroad performance may be threatened by line and yard congestion. Railroads are adding capacity by constructing additional main tracks in high-density corridors. Whether these investments are adequate to meet the needs of future traffic is a question that is beyond the scope of this paper.

As noted in the introduction, railroad performance is important from a multi-modal perspective. Highway agencies are hoping to reduce the growth of highway congestion by keeping long-haul freight on rail lines instead of highways. If railroad performance deteriorates as a result of congestion, the performance of the surface transportation system (as a whole) will be affected.

\section{Endnotes}

1. A signal aspect is a visual arrangement of signal lamps and/or positions that conveys information about the status of upcoming blocks when viewed from the direction of an approaching train. The indication of a signal is the information conveyed by its aspect. For example, a red-colored light in a certain position (the aspect) means "stop" or "stop and proceed" (the indication). The simplest traffic control system has only two aspects. The signals display only red (stop) or green (proceed). However, a two-aspect system does not provide the capacity necessary for busy rail lines. In North America, three-aspect signaling is the most common type. However, four- and five-aspect systems are sometimes used. As the number of aspects increases, so does the information conveyed by the signal.

2. Block signal systems are widely used in the United States. In such a system, the network is partitioned into segments (or blocks) of uniform lengths based on train stopping distances. The train separation distance is prescribed in number of blocks (e.g., 1, 2, or 3), depending upon the number of signal aspects and other traffic control factors. The number of signal aspects and block lengths are key factors in line capacity and network performance.

3. The R-1 report is the annual report of a Class I railroad to the Surface Transportation Board. In the United States, each Class I railroad is required to report information to the Surface Transportation Board for regulation. The R-1 report includes information on the miles of road and 
track owned or operated by a Class I railroad as well as operational statistics such as annual train-miles, car-miles, and ton-miles.

4. In some cases, it is possible to identify suspect R-1 data by using other variables as cross references. For example, the total tons and carloads handled in a year can be calculated from individual commodity subtotals in the QCS report and compared to the reported totals. Yard locomotive miles can be cross-checked using yard switching hours. Yard locomotive miles should be approximately equal to yard locomotive hours multiplied by typical switching speeds (e.g., 6 to $8 \mathrm{mph}$ ). Similarly, unit train car miles should be approximately equal to the carloads handled in unit trains times unit train miles. Several outliers that affected the analysis were discovered using these methods and by analyzing data series. The most reasonable carload and tonnage data were used. In some cases, the calculated totals were used instead of the reported totals. For one railroad, yard locomotive miles were zero or a very low number for several years. For this railroad, yard locomotive miles were computed by multiplying the yard locomotive hours by 6 mph. In total, these data substitutions were minimal.

5. This definition is included in the STB's instructions to Schedule 755, on Page 92 of the R-1 Annual Report form.

6. Singularity is a condition that occurs when one of a set of variables can be predicted from the values of the other variables in the equation.

\section{References}

American Association of State Highway and Transportation Officials (AASHTO). Freight Rail Bottom Line Report. Washington D.C., 2003.

Association of American Railroads (AAR). Railroad Facts - 2006 Edition, October, 2007.

Berndt, E.R., A.F. Friedlaender, J.S. Wang Chiang, and C.A. Vellturo. "Cost Effects of Mergers and Deregulation in the U.S. Rail Industry.” Journal of Productivity Analysis 4, (1993): 127-44.

Bitzan, J. and T.E. Keeler. "Productivity Growth and Some of its Determinants in the Deregulated U.S. Railroad Industry.” Southern Economic Journal 70, (2003): 232-253.

Cambridge Systematics, Inc. (CSI). National Rail Freight Infrastructure Capacity and Investment Study. Cambridge, Massachusetts, September 2007.

Kalay, S. and T. Guins. "Heavy Axle Loads: The Dollars and Sense Case." Railway Age, March, 1998.

Lee, T. and C.P. Baumel. "The Cost Structure of the U.S. Railroad Industry Under Deregulation." Journal of the Transportation Research Forum 28 (1), (1987): 245-53.

Martland, Carl. D. "Productivity and Prices in the U.S. Rail Industry: Experience from 1965 to 1995 and Prospects for the Future." Journal of the Transportation Research Forum 38 (1), (1999): 12-25.

Oum, T.H., W.G. Waters II, amd C. Yu. "A Survey of Productivity and Efficiency Measurement in Rail Transport.” Journal of Transport Economics and Policy 33(1), (1999): 9-42.

U.S. Surface Transportation Board. R-1 Class I Railroad Annual Reports to the Surface Transportation Board (R-1), 1987-2006. 
Wilson, Wesley W., "Cost Savings and Productivity Gains in the Railroad Industry.” Journal of Regulatory Economics 11 (1), (1997): 21-41.

Denver Tolliver is director of the Transportation \& Logistics graduate program at North Dakota State University and senior research fellow at the Upper Great Plains Transportation Institute. Tolliver earned a baccalaureate degree in geography from Morehead State and the Master of Urban \& Regional Planning and Ph.D. from Virginia Tech. He is a long time member of TRF and past president of the Agricultural Transportation Chapter.

John Bitzan is an associate professor in the College of Business at North Dakota State University. His research interests include market structure and performance, the impacts of regulatory change, and the determinants of wages. He has a Ph.D. in economics from the University of WisconsinMilwaukee.

Doug Benson has over 20 years experience in transportation research specializing in the analysis of railroad operations and in the development of computerized systems used for transportation analysis. Current research interests include railroad and multi-modal analyses, the development of a multi-modal research program incorporating detailed waterborne commerce data and the utilization of the Indian Reservation Roads database. He has supported the development of several computer programming systems and has published papers on personal computer and mainframe software systems, railroad database systems, and freight systems. 